\title{
JURISPRUDENCIA
}

Comentarios monográficos

Notas de Jurisprudencia

Contencioso-Administrativa

Notas de Jurisprudencia del Tribunal Europeo de Derechos Humanos 



\title{
COMENTARIO MONOGRÁFICO
}

\section{RESTRICCIONES A LA LIBERTAD DE EXPRESIÓN EN EL CONTEXTO DE ACTUACIONES TERRORISTAS}

\author{
Lorenzo Martín-Retortillo BaQuer \\ Catedrático emérito de Derecho Administrativo \\ Universidad Complutense de Madrid
}

\begin{abstract}
RESUMEN
La importancia que alcanza en nuestra sociedad la libertad de expresión no impide que ante circunstancias cualificadas pueda verse restringida, como sucede, por ejemplo, cuando aparecen mensajes terroristas, criterio que avala sin duda la jurisprudencia del Tribunal Europeo de Derechos Humanos.
\end{abstract}

Palabras clave: libertad de expresión; terrorismo.

\begin{abstract}
The freedom of speech can be limited in some special circunstances. On of them takes place when it appears terrorist mesages. The answer of the European Court of Human Rights is clear.
\end{abstract}

Keywords: freedom of speech; terrorism. 
1. Por fortuna, nuestra sociedad, en un contexto de organización colectiva en el que prima de manera destacada la libertad y en el que los derechos fundamentales ocupan lugar preeminente, ha asumido gozosamente el canon de la libertad de expresión, que se manifiesta de las más diversas maneras. De resaltar así el desarrollo que ha alcanzado el artículo 20 de la Constitución de 1978, con sus variadas alternativas, en la órbita del artículo 10 del Convenio para la Protección de los Derechos Humanos y las Libertades Públicas, auspiciado por el Consejo de Europa, y hecho en Roma el 4 de noviembre de 1950 (habitualmente llamado el Convenio Europeo de Derechos Humanos, que, en lo sucesivo se denominará «el Convenio»). Sin olvidar que este último precepto proviene directamente del artículo 19 de la Declaración Universal de Derechos Humanos, que hicieron las Naciones Unidas en París, el 10 de diciembre de 1948. Sabido es cómo el Consejo de Europa pretendió que cuanto antes pudieran hacerse efectivos con plenitud de garantías los más destacados derechos y libertades consagrados por la Declaración Universal, y de ahí que con encomiable rapidez se aprobara el Convenio Europeo, con la destacada novedad de erigir un tribunal —el Tribunal Europeo de Derechos Humanos o Tribunal de Estrasburgo- para que pudiera asegurar la plena virtualidad de tales derechos y libertades frente a posibles injerencias de los Estados. Estamos ante una realidad bien arraigada y no será preciso insistir más, pues se trata de algo obvio, para destacar con qué fuerza y vigor ha propiciado el Tribunal Europeo la citada libertad de expresión, que consagra su artículo 10. En el día a día, la jurisprudencia del Tribunal ha avalado con energía y sin desmayo los más amplios contenidos para la libertad de expresión desde una intensa tensión expansiva. De hecho, el dato real que ahora interesa es el de un fortalecimiento generalizado y efectivo de la libertad de expresión. Siendo de destacar el ámbito de la crítica política donde se auspicia la mayor amplitud posible para los temas de interés general.

2. A la vista de tal realidad no deja de constituir un vivo contraste la reciente Sentencia del Tribunal Europeo de Derechos Humanos en el asunto Bidart c. Francia, de 12 de noviembre de 2015 -definitiva desde el 12 de febrero de 2016 — , en la que, con normalidad, si bien en circunstancias cualificadamente excepcionales, se da por buena una onerosa restricción personal a la libertad de expresión impuesta a quien resulta ser el recurrente de la sentencia.

La explicación estribará en que, como es bien conocido, en puridad, la realidad es más bien compleja. Y es que, en efecto, lo que es el canon general puede conocer sin duda excepciones y restricciones, a la vista 
de que libertades y derechos no son valores absolutos sino que tienen sus límites y confines. Basta para recordarlo el apartado 4 del artículo 20 de la Constitución, o el apartado segundo del artículo 10 del Convenio Europeo. De acuerdo con este, en determinadas circunstancias expresamente previstas, y si se respeta la regulación, el ejercicio de tales libertades "podrá ser sometido a ciertas formalidades, condiciones, restricciones o sanciones». Adviértase el salto cualificado que ofrece la realidad: de todo tipo de alternativas, a restricciones y sanciones. Recuérdese, en efecto, que la libertad puede verse forzada a ceder para la defensa de muy cualificados valores como «la seguridad nacional, la integridad territorial o la seguridad pública, la defensa del orden y la prevención del delito, la protección de la salud, de la moral, la protección de la reputación de los derechos ajenos, para impedir la divulgación de informaciones confidenciales o para garantizar la autoridad y la imparcialidad del poder judicial». Se trata, como se decía, del completo apartado segundo del artículo 10 que consagra la libertad de expresión, un precepto en defensa de bien cualificados valores, del todo similar a los paralelos apartados segundos que complementan los preceptos sobre el derecho a la intimidad, la libertad de pensamiento, de conciencia y de religión o la libertad de reunión y asociación.

El supuesto de la sentencia nos va a situar ante una de las páginas patéticas de la reciente historia europea. Una Europa desolada por los desastrosos efectos de la Segunda Guerra Mundial, así como por las circunstancias que condujeron a ella, que parecía haber encontrado su tabla de salvación en el imperio de los derechos humanos - de los que el primero es el derecho a la vida-, tal y como empezó a fraguar la reacción en el verano de 1945 en la Carta de las Naciones Unidas y completada enseguida por una contundente serie de documentos, se encontró de golpe con la enorme sorpresa de quienes se inventaron unas aspiraciones políticas aberrantes, pero además con la insólita peculiaridad de que hacían de la violencia, la extorsión y el crimen su forma habitual de actuación política. De hecho, ciertas aspiraciones al nacionalismo, al utilizar como medios habituales de actuación incluso el asesinato, así como el chantaje y la extorsión, y numerosas modalidades torticeras y violentas - despreciando el normal actuar político instalado pacíficamente a disposición de todo el mundo-, propiciaron el salto cualitativo que llevaría a este nuevo concepto, al instalarse como algo habitual la práctica del terrorismo.

3. En efecto, quien figura como recurrente en la sentencia había sido, en el sur de Francia, el antiguo jefe de la organización separa- 
tista vasca Iparretarrak, condenado en numerosas ocasiones por muy diversos delitos, entre los cuales destaca, por su especial crueldad, el asesinato de dos miembros de los cuerpos policiales. En consecuencia, se irían enlazando muy diversas condenas de privación de libertad, por seis años, por veinte años e, incluso, en dos ocasiones, «la réclusion criminelle a perpétuité» (pág. 6). De forma que la presentación no puede ser más expresiva.

Pero a veces cambian las circunstancias: la conducta del condenado facilitaría que se le otorgara la libertad condicional, recordando la sentencia que el Gobierno precisa que se trata del primer caso de un condenado a reclusión criminal a perpetuidad en relación con actuaciones terroristas a quien se otorga la libertad condicional.

En Francia - como sucede en no pocos países-, tanto el Código de Procedimiento Penal como el propio Código Penal —en textos que la sentencia transcribe- permiten que en tales circunstancias se impongan a las personas afectadas una serie de «obligaciones generales», de «obligaciones especiales», o incluso de "obligaciones particulares suplementarias». Es así como inicialmente se le impusieron a Bidart determinadas obligaciones entre las que se consideran "generales»: atender a los requerimientos del juez de aplicación de penas y del correspondiente trabajador social, avisar de los cambios de residencia y de cualquier desplazamiento por más de quince días, recabar autorización para cualquier desplazamiento al extranjero, etc. También se le impusieron algunas obligaciones «especiales», como establecer su residencia en una determinada población, ejercer una actividad profesional o seguir estudios o una actividad de formación profesional, ingresar fondos para la indemnización de las víctimas del terrorismo o abstenerse de tener o llevar armas.

Así funcionaron las cosas con normalidad hasta que un día determinado sonaron las alarmas dado que Bidart participó en una manifestación pacífica ante la cárcel de Agen, en apoyo de los vascos que allí estaban detenidos, manifestación que sería aireada dado que daría cuenta de ella la prensa. Se entiende con normalidad que una grave condena pueda quedar en suspenso desde la discreción y el respeto, pero el panorama cambia ante el temor de que puedan surgir manifestaciones de apoyo sobre cualquiera de las conductas anteriores próximas a las que motivaron la condena. Y es que con el terrorismo no se juega, de ahí que no pueda tolerarse la pasividad ni la más mínima permisividad. El que un cualificado y conocido líder de una organización terrorista, condenado por crímenes atroces a muy severa condena, que obtenía libertad condicional a causa de su buena conducta, aprovechara su situación para seguir postulando sus viejas ideas, no podía dejar indiferente, 
muy presente siempre la cercanía de las víctimas de sus crímenes, en un territorio con ambiente bien enrarecido a causa de la activa presencia de los independentistas vascos. Es así como se va a alterar la situación del afectado, en la intención de imponerle algunas obligaciones particulares complementarias, en relación con las cuales es cuando van a aparecer las restricciones a la libertad de expresión. Se tomaron en cuenta diversas alternativas. Se barajó así el prohibirle manifestarse ante los establecimientos penitenciarios en apoyo de los detenidos por actos de terrorismo o a favor de asociaciones o movimientos relacionados con actos de terrorismo. Se consideró también el prohibírsele entrar en relación con cualquier militante a favor del separatismo vasco o con quienes apoyan a los condenados por actos de terrorismo. Hubo un interesante debate entre las distintas instancias jurisdiccionales pertinentes, y al final no prevalecieron las prohibiciones anteriores marcadas por su especial rigor. Sí se confirmaría, en cambio, la carga de abstenerse de la difusión de cualquier texto u obra audiovisual, de los que fuera autor o coautor, y que de alguna forma, en todo o en parte, se refiriera a los delitos por los que fue condenado, así como la carga de abstenerse de cualquier intervención pública relativa a tales infracciones. En una de las actuaciones judiciales se había constatado que el condenado era una persona tranquila y respetuosa que dedicaba la mayor parte de su tiempo a la redacción de sus memorias. Lo que lleva al juez de aplicación de penas a entender que, sin saber cuál era el contenido de tales memorias, pudiera Bidart sentirse animado a publicarlas y a hacer declaraciones referidas a los hechos por los que había sido condenado. Es así como tan significativa como insólita limitación quedaría confirmada, si bien se le recalcaría al afectado que se trataba únicamente de la prohibición de escritos o de declaraciones referentes a las infracciones por las que él había sido condenado (pág. 14). La decisión del juez de aplicación de penas sería confirmada por sentencia del Tribunal de Apelación de París, que destacaría «que dicha obligación se limita a prohibir cualquier comentario o cualquier apología de las infracciones cometidas y que en absoluto constituye una medida desproporcionada a la vista de la necesaria salvaguarda del orden público, por lo que en absoluto impide a Philippe Bidart manifestar sus convicciones políticas» (pág. 16). No tendría éxito el recurso de casación contra la prohibición confirmada, por lo que, agotada la vía interna, el debate se traslada al Tribunal Europeo de Derechos Humanos,

4. Es así como se llega a una sentencia bastante concisa pero tajante y terminante en cuanto a la argumentación y en la que, más allá de la 
situación concreta del afectado, va a tenerse muy en cuenta la incidencia sobre la sociedad en la que se sitúan las conductas debatidas. Va a resultar interesante en el supuesto la aplicación de la medida correctora a la vista de las circunstancias personales del afectado pero también teniendo muy en cuenta todo el contexto y el ambiente social en que se produjeron los hechos. Por otro lado, destaca el aspecto central de que la restricción a la libertad se justifica en cuanto pudiera facilitar actuaciones terroristas. No aparecen estas especialmente mencionadas en la lista de fines que enumera el antes referido apartado segundo del artículo 10 del Convenio Europeo, pero es obvio que tiene cabida indudable en varias de ellas: defensa del orden, persecución del delito, protección de derechos ajenos, etc. De esta forma indirecta, el terrorismo va a quedar íntimamente vinculado a la lista de causas que, excepcionalmente, permiten limitar la libertad de expresión.

No es demasiado abundante la jurisprudencia sobre restricciones a la libertad de expresión en relación con las actividades terroristas, pero no faltan las sentencias oportunas que ofrecen jurisprudencia consagrada y que permiten al Tribunal Europeo utilizar las conclusiones alcanzadas y manifestarse con energía. Si desde un punto de vista general interesa alguna sentencia referente a Turquía - como el caso Zana de 25 de noviembre de 1999-, es útil recordar que en un par de supuestos el Tribunal de Estrasburgo ha tenido ocasión de enfrentarse con las secuelas del terrorismo en el País Vasco francés, lo que le hace especialmente sensible a la situación particular de la zona, siendo de recordar especialmente los asuntos Association Ekin c. Francia, 2001, y Leroy c. Francia, 2 de octubre de 2008.

Volviendo a nuestro caso, el recurrente alega en su defensa que ha respetado escrupulosamente las obligaciones que se le impusieron inicialmente y que no ha hecho jamás apología de las infracciones por las que fue condenado. De ahí derivaría la falta de necesidad de la nueva restricción que, de hecho, conduciría «a prohibirle manifestar cualquier opinión sobre el actual contexto político del País Vasco, dado que las infracciones por las que fue condenado se produjeron en dicho contexto» (pág. 25). De hecho, argumenta también, la finalidad real de la obligación en cuestión sería la de prohibirle cualquier manifestación sobre la historia y el contexto político del País Vasco Norte.

El Gobierno contesta que la indudable «injerencia» se limitaba a comentarios y apología sobre los delitos contemplados, pero que no se le ha prohibido expresar sus convicciones políticas. Varios serían los fines que se pretendían alcanzar con la interdicción, incluidos todos ellos en el apartado segundo del artículo 10, ya recordado, como el mantenimiento 
de la seguridad pública, la defensa del orden y la prevención del delito, la protección de la reputación y de los derechos de terceros, en especial los de las víctimas de los delitos cometidos por el recurrente, así como los de sus familiares. En relación con este último punto, el Gobierno recalca que la liberación provisional condicional del demandante provocó muy viva emoción no solo entre los familiares de las víctimas sino, de forma más amplia, en la población local porque, por un lado, el mencionado hizo a la salida de la cárcel un discurso en vasco en el que declaraba que su alegría de estar libre no era completa dado que el Estado francés no reconocía al País Vasco; y, por otro lado, porque algunos meses después participó en una manifestación de apoyo a los detenidos vascos, a lo largo de la cual declararía que la situación de los detenidos vascos era injusta y que deberían ser liberados. De ahí que —insiste el Gobierno- se aspiraría a prevenir actos o conductas susceptibles de ofender a los familiares de las víctimas así como de evitar cualquier nueva infracción. Se trataría de asegurar, se razona, si, en línea con la jurisprudencia, se respeta un cierto equilibrio entre el derecho fundamental de cada uno a la libertad de expresión y el derecho legítimo de una sociedad democrática a protegerse contra las actuaciones de las organizaciones terroristas.

5. En relación con la vertiente de la proporcionalidad, se recalca el carácter excepcional de la medida, que el Código Penal la contempla exclusivamente para los delitos más graves - como los que implican la muerte de personas-, que se aplica solo en el periodo que dura la liberación condicional, por lo que habría quedado sin efecto al superarse esta. Pero se insiste en que la medida adaptada derivaba directamente de la situación y de la conducta del recurrente, muy presente que había ocupado una plaza destacada en la citada organización terrorista vasca, por lo que «se hacía necesario adaptar precauciones para que nadie viera en sus palabras o en sus comportamientos una incitación a nuevas manifestaciones de violencia» (pág. 31).

6. El Tribunal Europeo asume que tiene que llevar a cabo el control más escrupuloso. Se tiene muy en cuenta el carácter excepcional de la medida, referida solo a los autores de los delitos más odiosos y circunscrita al periodo de duración de la libertad condicional, y que no implica una incidencia global y general sobre las ideas políticas del afectado, circunscrita solo en cambio a referencias a los delitos por los que fue condenado.

El Tribunal Europeo advierte también que se trata no de una medida de carácter "administrativo», sino de una decisión de orden jurisdic- 
cional, abierta a los posibles recursos ante los tribunales pertinentes y, de hecho, se comprueba que se acudió al juez de apelación e, incluso, ante la Casación, lo cual añade un notable plus de garantía. Se trae a colación, salvadas las distancias, un curioso asunto que afectó al Reino Unido, el caso Nilsen, 9 de marzo 2010, en el que, aun en la línea habitual del tribunal de defender al máximo las opciones de quienes están privados de libertad, se daría por buena, sin considerar infracción de la libertad de expresión, la confiscación del manuscrito de las memorias de un recluso en el que relataba minuciosamente los delitos por los que había sido condenado.

El tribunal será especialmente sensible a las exigencias de mantener contenidas las opciones terroristas, a la vista también de la situación concreta: «En efecto, el Tribunal no puede ignorar el contexto en el que se situaría la restricción a la libertad de expresión del recurrente, es decir el dato de que ha sido decidida en relación con la liberación anticipada de un importante y conocido líder de una organización terrorista, condenado de forma señalada a reclusión a perpetuidad con motivo de homicidios cometidos en un contexto terrorista, así como el dato [...] de que tal liberación anticipada había suscitado muy viva emoción entre los familiares de las víctimas y, en sentido más amplio, en el seno de la población local» (p. 45). Recalco el uso reiterado y el énfasis que se pone en la expresión «el contexto».

Como advertía antes, el tribunal, al abordar sus casos, ha tenido oportunidad de familiarizarse con la situación que se vive en ese territorio. Uno de los supuestos que se cita reiteradamente y en el que se apoya el tribunal, es el caso ya citado Leroy c. Francia, 2 de octubre de 2008. Entra de lleno el problema de la restricción de la libertad de expresión también en el contexto de las actividades terroristas. En el supuesto, se trataba de una caricatura, forma de expresión de la que el tribunal con cierta indulgencia y tolerancia, suele reconocer el carácter satírico y provocador - aunque personalmente no comparta ese tono tolerante en el supuesto Vereinigung Bildender Künstler c. Austria, 23 de enero de 2007, que se cita como ejemplo-, aparecida en un semanario político de izquierda y abertzale, editado en el País Vasco francés, inmediatamente tras la destrucción de las Torres Gemelas, del World Trade Centre, de Nueva York, en un momento en que el mundo estaba impresionado por tamaña agresión que se había cobrado tan gran número de vidas humanas. Curiosamente, en la caricatura se va a parodiar un conocido eslogan comercial, de la marca Sony en concreto, con la siguiente leyenda: "vous en avez rêvé, Sony l'a fait», es decir, «lo que todos habíais soñado, lo ha conseguido Sony». Lo que sucede es que en la caricatura se utiliza 
de manera especialmente perversa y deformada: el dibujo muestra la polvareda al destruir los dos aviones los altos edificios, y la leyenda dice: "Nous en avions tous rëvé... le Hamas l'a fait», es decir, "lo que todos habíamos soñado... Hamas lo ha conseguido».

Obviamente, por poco importante que fuera la revista, el mensaje no pasaría desapercibido, provocando la consiguiente reacción. La jurisdicción penal apreciaría la existencia de un delito de apología del terrorismo, condenando al director de la revista y al autor - en concepto de autor y de cómplice, respectivamente-, a una multa de mil quinientos euros a cada uno, así como a la publicación íntegra de la sentencia a su costa. Tanto la apelación como la casación fracasaron, por lo que el asunto pasaría a la jurisdicción de Estrasburgo.

Destacaré que ante el Tribunal Europeo, entre las circunstancias del caso y la convicción de que no puede banalizarse el terrorismo, va a cobrar especial significado la consideración del «contexto». Ya lo apuntaría el Gobierno en su alegato: «Considera esencial el contexto de la publicación litigiosa. Ante todo, la fecha de la publicación, inmediatamente tras los atentados, momento en que la opinión pública estaba especialmente afectada. Pero también hay que dedicar atención al lugar, dado que la publicación se lleva a cabo en una región en la que el riesgo terrorista está lejos de haber desaparecido, y en la que tales apologías, que conducen a una banalización de actos muy graves, pueden dejar importantes consecuencias» (p. 30).

El Tribunal Europeo, que entiende que de ninguna manera puede justificarse la publicación, y que no se pueden trivializar cosas tan serias como la muerte de tan gran número de personas a consecuencia de una actuación especialmente criminal, sale directamente al paso de la manifestación del recurrente cuando afirma que no hacía sino crítica al imperialismo americano: «El Tribunal no comparte el análisis del recurrente $[\ldots]$ —se dirá-. En su consideración conjunta con el texto que la acompaña, la obra no critica el imperialismo americano sino que sostiene y glorifica su destrucción por la violencia. A este respecto, el Tribunal se apoya en la leyenda que acompaña al dibujo y constata que el recurrente está mostrado su apoyo y su solidaridad moral con los autores del atentado del 11 de septiembre de 2001. Según se deduce de los términos empleados, el recurrente juzga favorablemente la violencia perpetrada sobre miles de civiles y ataca la dignidad de las víctimas» (p. 43). Se resalta también la inmediatez temporal y se asume sin falta el argumento ambiental: «De forma especial no se puede minusvalorar el impacto de un tal mensaje en una región políticamente sensible; a pesar del carácter limitado del hecho de la publicación en el semanario en 
cuestión, el Tribunal constata que dicha publicación conllevó reacciones capaces de activar la violencia demostrando su impacto efectivo sobre el orden público en la región» (p. 54).

En conclusión, se consideran suficientes los motivos y se aprecia que era una sanción moderada, por lo que, «en tales circunstancias, teniendo en cuenta en particular el contexto en el que fue publicada la caricatura cuestionada, el Tribunal considera que no era desproporcionada al legítimo fin perseguido la medida tomada contra el recurrente» (pág. 47). En consecuencia, por unanimidad, se estima que no ha habido violación de la libertad de expresión. Muy de destacar por tanto que el Tribunal Europeo se mantuviera firme en su línea de condena sin dar valor a la artificiosa argumentación del recurrente. Lo que es, es, sin que quepa tergiversar los hechos con invenciones ingeniosas.

7. Me parece de interés considerar conjuntamente ambas sentencias: bien diferentes en cuanto al alcance de la medida restrictiva de la libertad de expresión, la solución queda franqueada directamente al apreciarse la incidencia del terrorismo. En un caso, al exaltarse directamente la violencia criminal, por mucho que sea a través de una caricatura con su vocación de acto «lúdico». Acierta el tribunal al apreciar que no hay «broma o juego», sino desprecio directo a miles de víctimas, así como insolidaridad ante una opinión pública consternada. En el otro supuesto, se trata de algo mucho más sutil, que juega además desde una perspectiva preventiva. Pero resulta evidente que lo que se pretendía era evitar cualquier conducta que tendiera a jalear de alguna manera actuaciones vinculadas al terrorismo. Se trata de una bien peculiar a la par que concreta restricción de la libertad de expresión. Y el otro elemento común, que bien se cuida de resaltar el Tribunal Europeo de Derechos Humanos, el significado de producirse las actuaciones en un territorio donde se ha dejado sentir con fuerza la lacra del terrorismo, lo que reclamaba, por ende, todo tipo de precauciones. Significado, así, del aspecto territorial a la hora de fijar las circunstancias del caso.

8. Una vez concluido y antes de enviar el comentario a la imprenta, he tenido la grata oportunidad, casi fortuita, de leer en el Boletín Oficial del Estado de 26 de julio de 2016, la reciente Sentencia del Tribunal Constitucional 112/2016, de 20 de junio, que va a abundar en el mismo tema, bien que desde diversa perspectiva, incorporando elementos interesantes al razonamiento. Ahora es un amparo en el que el reclamante entiende que tanto su libertad ideológica como su derecho a la libertad de expresión han sido cercenados, en cuanto resultó condena- 
do penalmente por un delito de exaltación del terrorismo. En concreto, el recurrente, Tassio Erkizia Almandoz, había tenido una actuación como orador principal en el acto celebrado como recuerdo y loa del antiguo militante de ETA, conocido con el alias de "Argala», cuando se cumplían treinta años de su fallecimiento (recuérdese que Argala había muerto asesinado). Sobre la misma realidad de fondo - un nacionalismo violento e inmisericorde-, se empalma así el supuesto de Iparraterrak, en Francia, con uno de ETA en España, no sin olvidar que esta última organización fue mucho más sanguinaria. Ezquiaga sería procesado y condenado debido a su intervención dado que los hechos probados se consideraron constitutivos de un delito de enaltecimiento del terrorismo, previsto y penado en los artículos 578 y 579.2 del Código Penal. Se insiste en la sentencia que no se trata de un mero acto político sino de un acto de exaltación de un cualificado miembro de ETA, conocido solo, aparte de su trágico final, por sus reiteradas actuaciones en el campo del terrorismo etarra. La originaria sentencia de la Audiencia Nacional sería recurrida en casación, alegándose vulneración tanto del derecho fundamental a la libertad ideológica (artículo 16.1 CE) como de la libertad de expresión (artículo 20.1.a CE). El Tribunal Supremo denegaría el recurso de casación, estimando correcto el proceder de la Sala así como acertada la argumentación, sentencia que contaría con un voto particular discrepante.

Similar argumentación se lleva ante el Tribunal Constitucional en el recurso de amparo. El Ministerio Fiscal se opone con energía al otorgamiento del amparo, alegando, con base en la jurisprudencia del Tribunal Constitucional y del Tribunal Europeo de Derechos Humanos, que la libertad de expresión no puede ofrecer cobertura frente al llamado «discurso del odio». Comparecería también en el recurso la Asociación Dignidad y Justicia, manifestándose igualmente en contra del otorgamiento del amparo.

El Tribunal Constitucional elabora una cuidadosa sentencia donde se destaca ante todo como principio el significado de la libertad de expresión. Se precisa, en especial, que «la concreta cuestión de la eventual incidencia que podría tener la sanción de un delito de enaltecimiento del terrorismo en el derecho a la libertad de expresión no ha sido todavía objeto de ningún pronunciamiento de este Tribunal mediante sentencia». Pero se traerá a colación la doctrina elaborada por el Tribunal en relación con la constitucionalidad de los tipos penales relativos a la negación y difusión de ideas que justifiquen el genocidio, y se trae apoyo en la jurisprudencia del Tribunal Europeo de Derechos Humanos, en el sentido de que la libertad de expresión no puede amparar los men- 
sajes que impliquen incitación a actos terroristas (asunto Hohefeld c. Alemania, 20 de enero de 2000). Tras una minuciosa valoración de los argumentos, se termina rechazando el amparo. A la vista de la sólida fundamentación del fallo, sorprende un voto particular disidente del magistrado Juan Antonio Xiol Ríos.

9. Tras lo que acabo de recoger, cumple completar la constatación que antes comenzaba a ofrecer: bien diferentes supuestos fácticos pero presididos todos ellos por la idea central de la presencia del terrorismo. Se ofrecen así tres variantes legítimas de incidencia restrictiva sobre la libertad de expresión. De hecho, por esta vía indirecta, nos encontramos con que se consagra con decisión que el terrorismo es una de las causas que permiten cercenar la libertad de expresión. De una parte, la condena inequívoca de la viñeta exaltadora. En segundo lugar, esta peculiar llamada de atención a quien cometió gravísimos delitos para que no hable sobre ellos. Hipotética advertencia preventiva que, dentro de su zona de dudas, quiere dejar las cosas bien claras para evitar males mayores. Apareciendo en tercer lugar esta vertiente menos insólita de quienes de alguna forma ensalzan o enaltecen actuaciones terroristas, y por ello serán castigados penalmente. Siendo de admirar en los tres supuestos la determinación y finura del respectivo tribunal, yendo al fondo y desvelando lo que hay, sin dejarse llevar de las apariencias: no es el recuerdo a una persona fallecida, no es una opinión política sobre el capitalismo, no es la innegable libertad de tener ideas políticas propias. Resulta decisivo que se llame a cada cosa por su nombre, y que se hable así de terrorismo donde es eso lo que hay.

Sin duda, resulta rigurosa tal forma de proceder, más cuando afecta a bien tan decisivo como es la libertad de expresión, pero en los tres casos hay un importante valor jurídico que proteger. Aparte de que se trata de situaciones límite y excepcionales, en las que ha mediado una cuidadosa intervención judicial, abierta siempre, por supuesto, a los correspondientes recursos. Pero teniendo muy claro, como razona directamente el Tribunal Constitucional apoyándose en los casos del Tribunal Europeo de Derechos Humanos, que no cabe incluirlas dentro de la cobertura otorgada por el derecho a la libertad de expresión o ideológica, «en la medida que el terrorismo constituya la más grave vulneración de los derechos humanos en aquella comunidad que lo sufre, porque el discurso del terrorismo se basa en el exterminio del distinto, en la intolerancia más absoluta, en la pérdida del pluralismo político y en definitiva en el aterrorizamiento colectivo». 